\title{
Organisational competence in project management -new perspectives on assessing and developing organisations
}

\author{
Reinhard Wagner \\ German Project Management Association, Nuremberg
}

\begin{abstract}
Organisations need to cope with a lot of challenges in an increasingly complex environment. As projects act as means to adapt to dynamic change the competence of managing these projects gains more and more attention. So far, the competence of individuals was seen as main the lever to improve the performance in projects. But the competence of an organisation is more than the collective competence of all individuals; it is rather the combination of individual competences, together with strategic, structural and cultural factors and the availability of suitable resources that helps an organisation to compete. The concept of organisational competences in project management is an integrative and holistic approach showing the competences needed to cope with projects in a complex environment.
\end{abstract}

Assessments could be used to derive the development needs for an organisation. Taking into account the approach of organisational competences in project management, the assessment should cover more than the processes. For instance it should take a closer look at the strategy and how projects are selected and prioritised to increase the effectiveness. Furthermore, it should check how project work is organised and embedded in the corporate culture to improve efficiency.

The gap between actual and target state as a highlighted result of an assessment leads to the need for action. Top management decides what should be done and how the objectives could be reached. One way to start a project is to improve the project management top-down. It will be argued that this as well the bottom-up approach is a way of improving organisational competence, giving space to manoeuvre for the people involved and letting self-organisation help the organisation to develop in a coevolutionary way.

Keywords: Organisational competence, project-oriented organisation, project management assessment, co-evolutionary development

\section{Introduction}

Project work is steadily gaining importance for the economy, public services and nonprofit organisations, requiring project management to be handled more professionally and the entire organisation to be adjusted to the principles of project economy. Predatory competition forces organisations to realise projects within tight deadlines, with limited resources and at top quality. Thus, project management must be developed continuously. For many organisations, this results in a comprehensive change process not only including the strategic and cultural orientation, but also the structure and process organisation, project management methods and (software) tools, human resources development among many other areas. 
What is the status quo of the organisation's project management? How can it be assessed? What are the crucial levers and the necessary development actions? These and other questions can be answered by applying the holistic concept of organisational competence in project management.

\section{Development of project-oriented organisations}

Organisations are subject to constant change. Such change is not only caused by globalisation, which is often considered a menace, but also by a diversity of changes within an organisation's area of influence. These may be changes in the core values of society (e.g. the careful use of resources) or employees' increasing demands in their workplace (e.g. the desire for more demanding tasks). These challenges require solutions in order to ensure the organisation's long-term survival and success. If an organisation is understood as a social system that is made up of individuals cooperating within a framework of rules, then a comparison with the development processes of nature or mankind is a suitable means of explaining the development of organisations.

According to Charles Darwin's theory of evolution, natural selection is one of the major mechanisms that drive the development of nature and living creatures. In the long run, only those organisms will survive that are able to adjust to their environment ('survival of the fittest').

In nature, adaptation is realised by variation and reproduction, i.e. changes of the genetic code across the generations. If reproduction works well, individual life forms quickly enter into a state of competition leading to natural selection. Accordingly, evolution can be defined as continuous adaptation to a changing environment.

The same principles apply to the economy, where companies must adjust to constantly changing environmental conditions such as increasing customers' demands in new markets, new competitors or lack of resources. In the long run, only those companies will survive that are among the most successful in adjusting to environmental conditions and in finding solutions to the challenges of their time.

Adaptation is determined by the following criteria (Becker 2010: 62):

- Reliability: Within the context for which it has been developed, adaptation must function reliably.

- Effectiveness: To be able to solve a problem, the problem solution must be especially effective compared to other solutions and the solutions devised by other parties (market participants).

- Efficiency: As compared to other solutions, the solution selected may only have slight disadvantages and be more cost-efficient.

- Accuracy: The solution must be targeted at a specific objective.

- Context: The solution must function within the context of the given environment and resources.

- Cultural connectivity: The solution must comply with the established rules of society, spirit of age, etc.

Adaptations are usually not a continuous process, but are mostly reactions to significant change of the environment. For example, many adaptations were necessitated by the realestate and financial crisis in recent years. The effects can still be felt today in many areas 
of public, professional and private life. Complexity, uncertainty and dynamic development are keywords often used in the context of such changes. Successful organisations, however, may profit from these challenges, responding with creativity, flexibility and intelligent adjustment to changed conditions.

Project management hence plays a central role as projects are a means of implementing a strategy, turning innovation into successful products, helping acquire new markets, and facilitating the most efficient and effective use of scarce resources. After all, the corresponding changes are usually realised in the form of projects.

Project-oriented organisations also undergo a development process whose dynamics may vary depending on environmental influences. The development is influenced by many factors. For example, the extent of project work is determined by the area in which the organisation is active. A manufacturer of a series of products will undertake a smaller number of projects than a consulting agency or a provider of engineering services. Market orientation is another key factor as customers expect an individual response to their demands. This is what usually triggers a project, whereas departments with a rather internal orientation (headquarters, administrations etc.) are less inclined to do project work.

'The more global the business in an industry, and the more know-how the products and services of the company incorporate, the more the company is subject to the globally interconnected dynamics of change of the markets. The higher the level of environmental dynamics and the complexity of the business, the more proactive management should pursue the transition from realising individual projects to a project-oriented company.' (Bea, Scheurer \& Hesselmann 2012: 23)

Figure 1 shows a possible development continuum for project management. It is influenced by environmental conditions and the company's strategic orientation with respect to the competition. The development continuum shown begins with the 'management of projects' (focus on realisation of individual projects only), and evolves via 'management by projects' (focus on strategy-compliant management of multiple projects) to the 'project-oriented company' (focus on project-driven structure and management of company).

This idea is based on the assumption that there are only a few projects to be managed at the beginning, and that these are to be realised as efficiently as possible, and that most other activities are still performed within the framework of a function-oriented organisation. If now the number of projects and, accordingly, their importance increases, it becomes necessary to coordinate the multitude of projects and to adjust them to the company's mission. Multi-projects management, i.e. program management (operational) and project portfolio management (strategic) gain in importance and must ensure that projects are realised not only efficiently, but also as effectively as possible. 

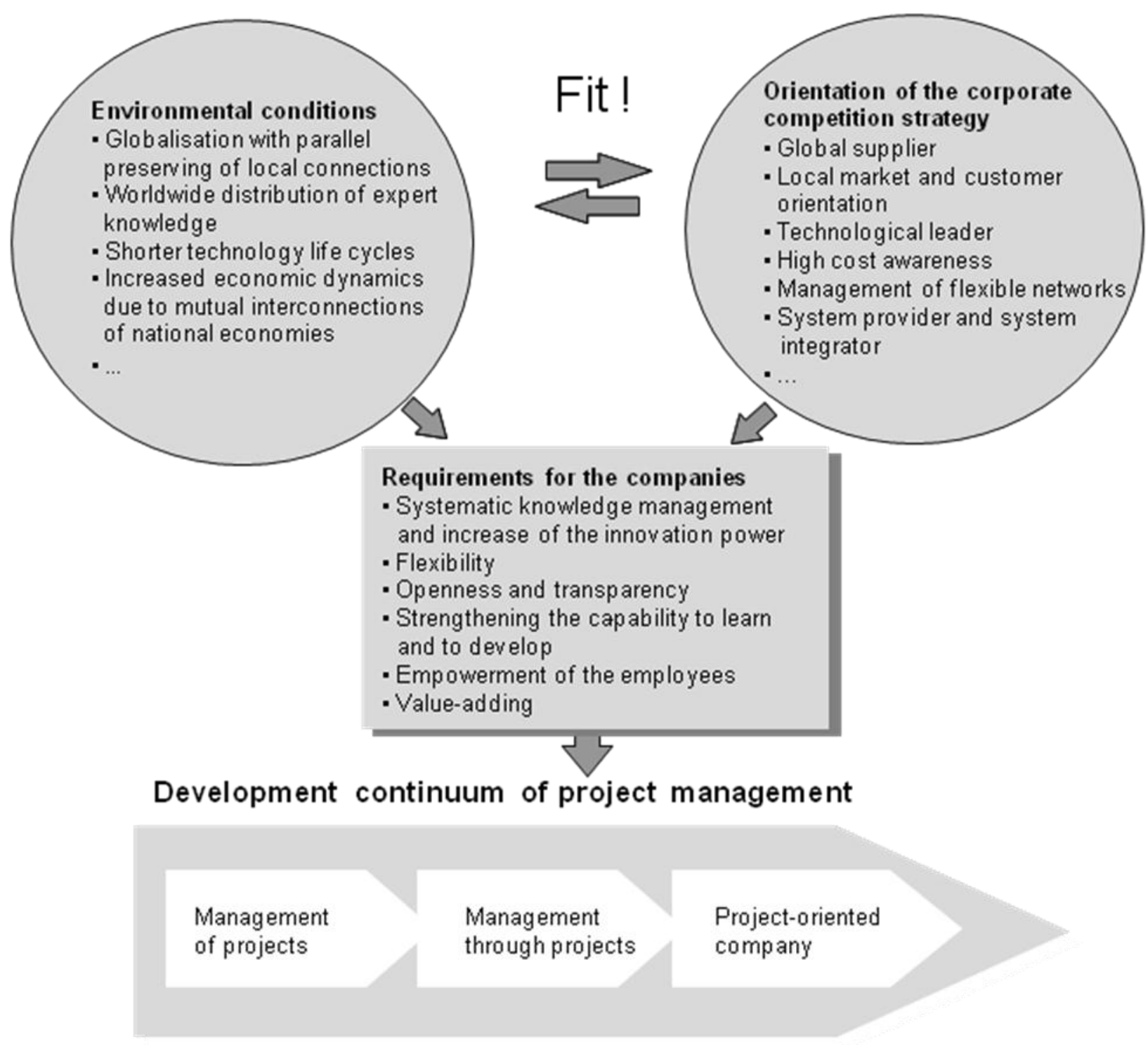

Figure 1: Strategic fit of project management

The way in which projects are organised is affected by market orientation and the complexity of the projects. As complexity increases, the importance of standards increases as well - they are serving as means of communication, framework of cooperation and tool for the enhancement of efficiency and effectiveness. Standards also help to achieve synergies, to improve transparency, to make projects comparable, and to support learning during and from projects. Therefore, they play an important role in assessing and developing the organisation.

\section{Organisational competence in project management}

Since the 1980s, the competence perspective has received more and more attention in research as well as in practice. It can be seen as 'the common denominator of a series of theories and research traditions within contemporary theories of the firm and strategic management. The concept includes resource-based theory (Wernerfelt 1984), dynamic capabilities theory (Teece, Pisano \& Shuen 1990; Langlois 1992) and knowledge-based theory of the firm (Demsetz 1988). Common to these theories is the decisive importance 
given to the firm's internal, rather than to its external conditions for understanding its competitive market position.' (Knudsen 1996: 13)

Competence in general could be defined as the 'ability to do something successfully or efficiently' (Oxford Dictionaries 2012) or as an 'idiosyncratic knowledge capital that allows its holder to perform activities — in particular, to solve problems — in certain ways, and typically do this more efficiently than others. Because of its skill-like character, competence has a large tacit component, and is asymmetrically distributed. It may reside in individuals, but is in the context of the theory of the firm and strategic management perhaps best seen as a property of organizations rather than of individuals.' (Foss 1996: 1)

In project management the term 'competence' has generally been used for individuals. The well-acknowledged Competence Baseline of the International Project Management Association (IPMA) defines it as the 'demonstrated ability to apply knowledge and/or skills, and, where relevant, demonstrated personal attributes.' (IPMA 2006: 3) The Project Manager Competency Development Framework (PMCD) of the Project Management Institute (PMI) defines it as the 'demonstrated ability to perform activities within a project environment that lead to expected outcomes based on defined and accepted standards.' (PMI 2002: 2)

Nevertheless, the term could be applied not only to individuals but also to a group of people, e.g. a team. In such a case, competence is more than the collective competence of its individuals. The coherence of the team with dynamic interactions between the members and relevant stakeholders constitutes a social system with special characteristics of competence. Following on this idea, the term 'competence' could also be applied to social systems such as organisations, networks and societies.

When applied to organisations, competence could be seen as 'first, a consistent conceptualization of firms in terms of competence: firms are seen essentially as repositories of competence. And, second, it is firms' ability to accumulate, protect and eventually to deploy competences to product markets that is seen as determinative of their long-run competitive advantages. Moreover, firms' competence endowments codetermine their boundaries, notably their degree of diversification. This view ... is also emerging within economics, particularly in the evolutionary theory of the firm ...' (Foss 1996: 1)

Depending on the research focus, several other definitions can be found to describe the concept of competence in conjunction with an organisation. For example, the core competences of an organisation could be defined as 'the collective learning in the organization, especially how to coordinate diverse production skills and integrate streams of technologies' (Prahalad \& Hamel 1990: 82); 'an organisation's internal capability to reach stakeholder-specific situation-dependent goals, where the capability consists of the situation-specific combination of all the possible individual-based, structure-based and asset-based attributes directly manageable by the organisation and available to the organisation in the situation' (Taatila 2004: 88); or 'the firm's ability to integrate, build and reconfigure internal and external resources and competencies to address rapidly changing environments.' (Teece, Pisano \& Shuen 1997: 516) 
Building on these definitions, organisational competence in project management could be defined as an organisation's internal capability of achieving its targets by smartly combining, applying, managing and developing its available individual, strategic, structural and cultural competences as well as its assets when performing project work. This definition still includes the competences of the individuals involved. In addition, it mentions competences that enable the individuals to perform in projects. The strategic competence is the organisation's management competence to develop a strategy for project management and align projects, programs and project portfolios with corporate strategy. The structural competences are the inherent processes, routines, roles and responsibilities usually described in standards and applied through projects and programs. The cultural competence is the project-oriented culture shown by the stakeholders and applied in projects. Usually, it is part of the corporate culture with its beliefs, values and behaviours. Finally, assets could be understood as all tangible and intangible resources available for project work.

Figure 2 shows all the ingredients of organisational competence in project management together with their relationships. Based on the market and environmental conditions, the organisation's management develops a suitable strategy and aligns the project business accordingly. Processes and organisational structures as well as a project-oriented culture should enable it to achieve its strategic goals.

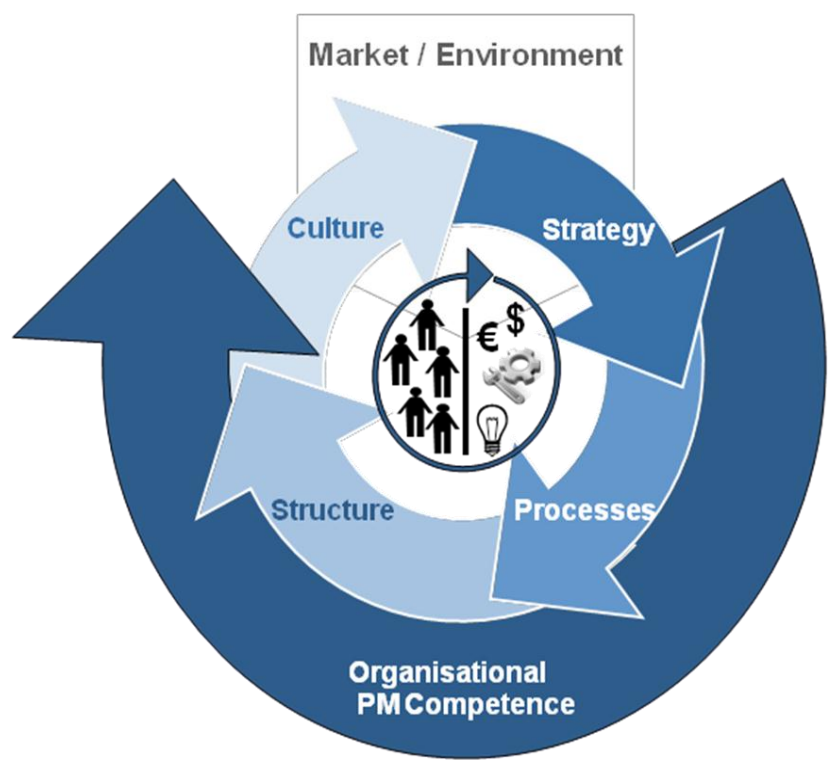

Figure 2. Organisational project management competence (Rietiker et al 2011: 16)

The organisation's management plays a decisive role in the development of the organisational project management competences. Management must analyse the environmental conditions and determine the strategic course that will allow the organisation to meet the challenges of its time. In rapidly changing environments, there is obviously a greater need to reconfigure and develop the competences. In an organisation strongly involved in project-related work, the organisational competences in project management should be developed as core competences in order to cope with all the requirements. 
The capacity to achieve new forms of competitive advantages for the organisation, for instance through organisational development projects, is an essential part of this concept. "The term "dynamic" refers to the capacity to renew competences so as to achieve congruence with the changing business environment; certain innovative responses are required when time-to-market and timing are critical, the rate of technological change is rapid, and the nature of future competition and markets difficult to determine.' (Teece, Pisano \& Shuen 1997: 515)

The question is: how does the organisational competence develop over time? This leads back to the evolutionary character of the development. Organisations and their respective management have choices. Following the basic principles of evolutionary theory, e.g. variation, selection and retention, organisations must adapt and select to be competitive in their respective environment. Thus the environment (e.g. competitors, customers, and suppliers) plays an important role for the organisation developing in a co-evolutionary way. 'A co-evolutionary approach assumes that change may occur in all interacting populations of organizations, permitting change to be driven by both direct interactions and feedback from rest of system ... For co-evolution to occur the population must consist of heterogeneous firms that have adaptive/learning capability and are able to interact and mutually influence each other.' (Volberda \& Lewin 2003: 2114)

Obviously the development of all organisations in a certain domain is highly interwoven. What can top management do to influence this co-evolution in the right direction? Volberda and Lewin (2003) argue that top managers could enable the organisation by nurturing and maintaining a maximum of self-organisation and sustaining the concurrent exploration and exploitation in the respective environment. 'However, managed selection adaptation processes require continuous attention. It is exactly this feature of continuous attention or managerial intentionality that distinguishes organization resilience or secondorder renewal capabilities of successful long-lived organizations from non-coevolving organizations with a focus on short-term exploitation.' (Volberda \& Lewin 2003: 2132)

Helfat and Peteraf (2003) argue that competitive advantage and disadvantage comes about over a period of time and also may shift over time. Therefore, they developed the 'capability lifecycle' to show the evolution over time of all resources and capabilities that form the basis of an organisation's competitive advantage. 'The capability lifecycle depicts a general pattern and set of possible paths that characterize the evolution of an organizational capability ... The lifecycle of a new capability in a new-to-the-world organization begins with the founding stage, which lays the basis for subsequent development of the capability. A development stage follows this initial stage, marked by gradual building of the capability. Eventually, capability building ceases and the capability reaches the maturity stage.' (Helfat \& Peteraf 2003: 1000)

Maturity models describe distinct development states of an organisation in a domain, e.g. 'within OPM3, maturity comprises not only the state of optimal performance within project, program, and portfolio management, but also the organization's evolution toward that state as illustrated by Standardize, Measure, Control, and continuously Improve (SMCI)' (PMI 2008: 184). Thus, the concept of project management maturity highlights the development path and states achieved whereas organisational competence in project management is an organisation's internal capability, driving this development coevolution and reaching the desired states. 


\section{Assessing organisational competence in project management}

Organisations are interested in analysing their current status quo in a certain field and improving it to a higher level. This applies to the field of project management as well. In Germany, two project management assessments were developed in the mid 1990s. One was based on the European Foundation of Quality Management (EFQM) model for assessing single projects and evaluating them for the Project Excellence Award. The other, called PM Delta, was based on the standard DIN 69904 and targeted the entire project management system of an organisation.

In the United States, Harold Kerzner developed the Project Management Maturity Model (PMMM). This tool helps to measure an organisation's project management maturity, i.e. the improvements achieved in the past, and to decide the steps needed to be taken for continuous development in the future (Kerzner 2005). Kerzner's PMMM together with the Capability Maturity Model (CMM) of the Software Engineering Institute (SEI) have been very influential in the development of other assessment models such as the PMI's Organisational Project Management Maturity Model (OPM3) and the British Cabinet Office's Portfolio, Programme and Project Management Maturity Model (P3M3). All these tools basically build on a process approach, looking at the existence of standards and their application, evaluating them on a five-level scale from an 'initial' to a 'continuous improvement' state. Figure 3 shows the comparison of the Maslow's (1943) 'needs pyramid' with the maturity levels of an organisation in the field of project management.
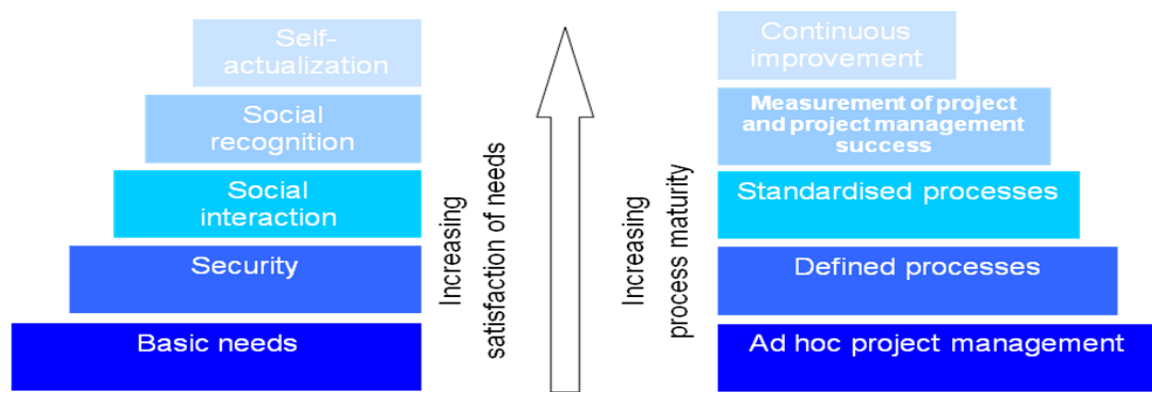

Figure 3: Comparison of needs satisfaction and process maturity (Wagner 2010: 27)

At the lowest level there are no standards. Project management is applied by individual project members on the basis of individual experiences. At the next level, some standards have been introduced (e.g. processes, rules, methods). But they are far from being sufficient, only cover some subareas and only some of them are applied. At the third level, standards are available for almost all areas of project management and are consistently implemented. At the fourth level, project management and its performance are monitored and controlled (with regard to quality). At the fifth level, a continuous improvement process is added. Similar to the need for self-actualisation, the scale is also open towards the top; continuous improvement is thus never completed.

Experience shows that the two uppermost maturity levels are difficult to reach. They require a high degree of top management attention and considerably high investments. For many organisations a medium maturity level is sufficient. This depends on the 
strategic orientation, the situation within the company and external influences, such as market, project and customer requirements.

The more the strategic impact of projects on organisations is recognised, the broader the scope of models need to be, looking at more aspects than processes for the management of a project. For example, the second edition of the OPM3 model was upgraded and based on the concept of Organizational Project Management (OPM), which is 'the systematic management of projects, programs, and portfolios in alignment with the organization's strategic business goals' (PMI 2008: 9). Furthermore, it introduces Organizational Enablers (OE). They are perceived to be 'Best Practices which facilitate the implementation of Best Practices, but also help make organizational improvements sustainable. The presence of Organizational Enablers indicates that an organization has matured to the point of establishing a stable OPM practice environment and has embraced the disciplines of project, program and portfolio management to achieve this ... For instance, the Organizational Enabler "Establish OPM Leadership Program" will help sustain a group of leaders who can champion OPM3 improvement plans.' (PMI 2008: 33)

The IPMA, as the world's first project management association, actively promotes competence in project management to businesses, organisations and government agencies around the world. It has offered certification for individuals since 1998 based on the IPMA Competence Baseline (ICB), showing the competences needed at four different levels (IPMA 2006). In addition, the IPMA's Project Excellence Award recognises the achievements in projects based on the Project Excellence Model, assessing the application of project management and the results achieved.

Since 2012, the IPMA has offered a new service for the assessment and certification of organisations in the field of project management, called the IPMA Delta. It is based on the concept of organisational competence in project management, using the ICB to assess the competences of selected individuals, as well as the Project Excellence model to assess the application of project management and the results of selected projects and programs. Further, the assessors use a multidimensional questionnaire to assess organisational competence in project management, which looks at the four dimensions of governance, processes, people and context, breaking them down to 22 elements. These are based on leading, modern, international project management standards and cross references. Figure 4 shows the three modules of the IPMA Delta and their interrelations.

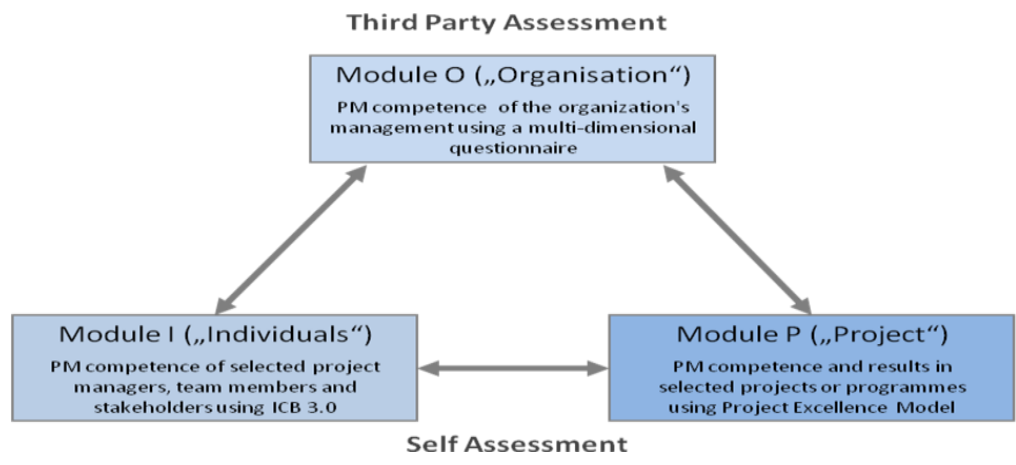

Figure 4: Modules of IPMA Delta ${ }^{\circledR}$ 
Figure 5 shows the five IPMA Delta Competence Classes and their characteristics. In a Class 1 organisation, experienced project managers have positive effects on project management but the organisation has not yet implemented standards, structures and processes for the management of individual projects, programs and project portfolios. In a Class 2 organisation, initial standards, structures and processes exist but only some of them are really applied. In a Class 3 organisation, project management standards, structures and processes have been fully implemented and are also applied. To reach Class 4, an organisation must prove that the application of project management is controlled and, if appropriate, corrective actions are taken. A Class 5 organisation is continuously developing.

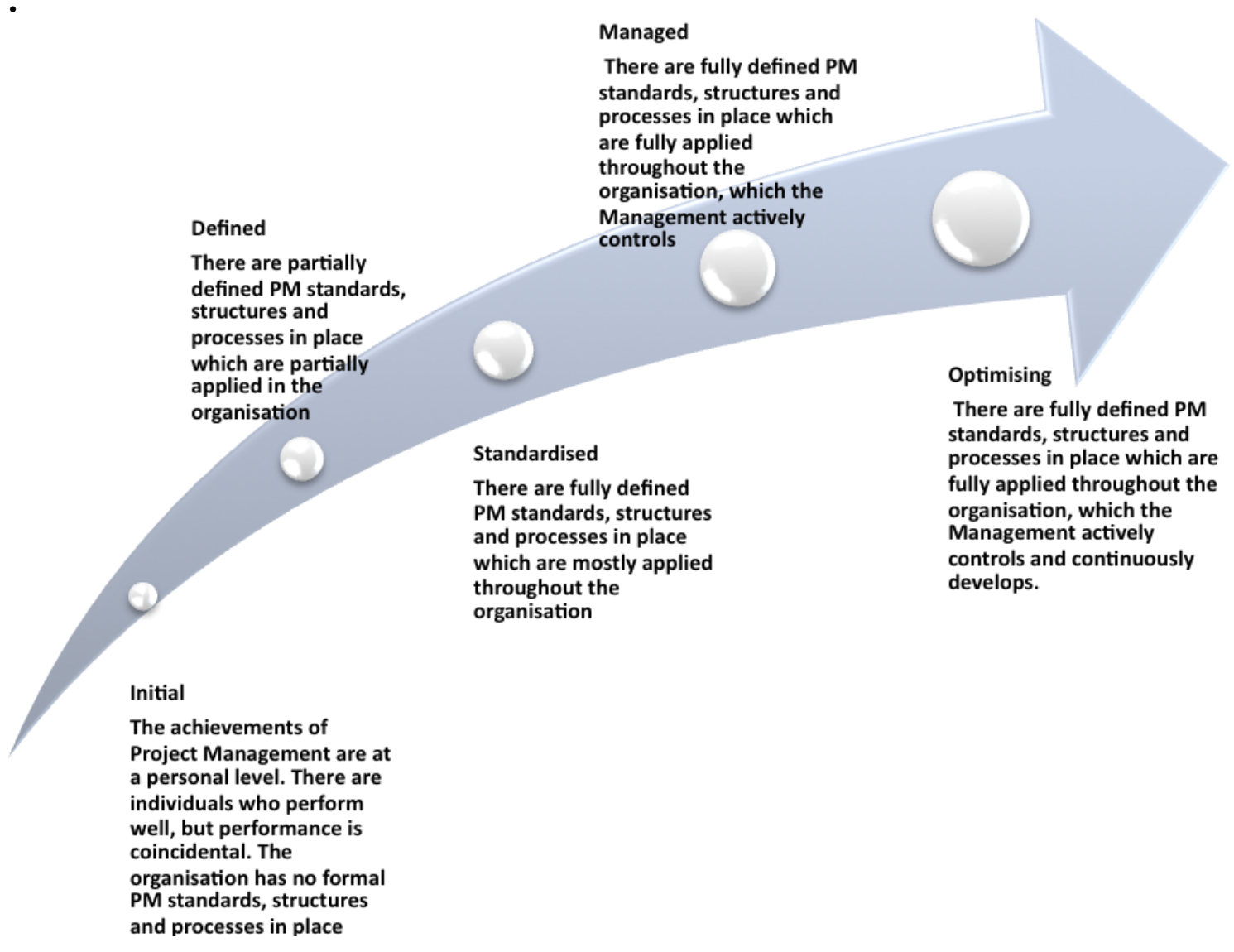

Figure 5. IPMA Delta ${ }^{\circledR}$ supports continuous development

Assessments help the organisation to understand the actual status quo in project management with the strengths, best practices and areas for improvement. After defining a reference value, development needs can be derived from looking at the delta. Further, the project management assessment helps to decide on long-term development strategies and measures. It can be used to do internal or external benchmarking. Finally, continuous improvement through assessment leads to better results in projects and programs, which increases the competitive edge. Figure 6 shows the objectives for the use of assessments in project management. 


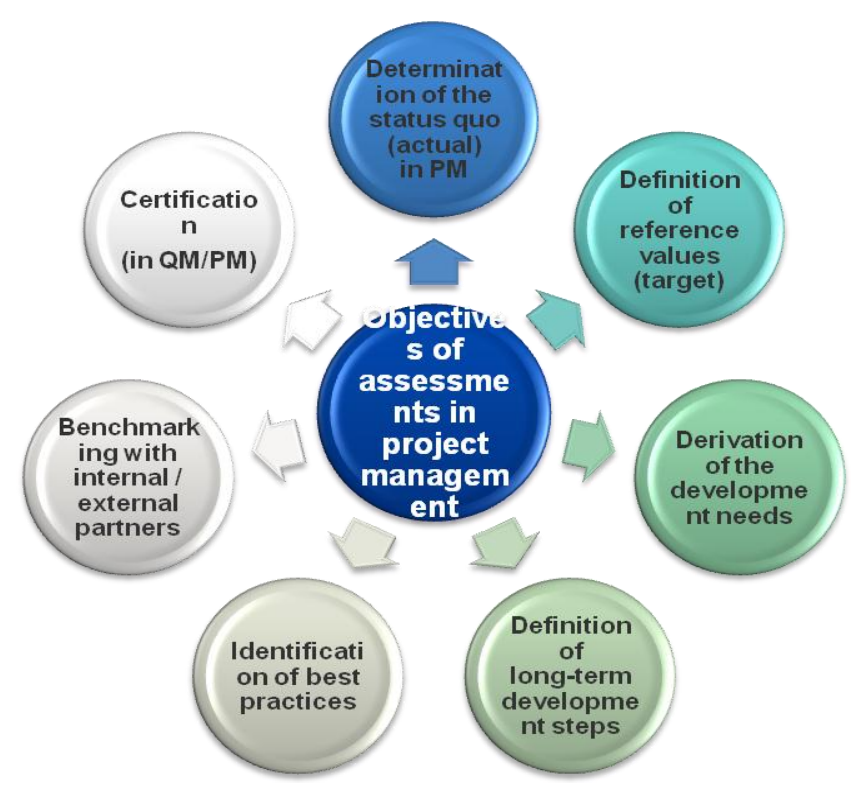

Figure 6: Objectives of assessments in project management (Wagner 2010: 25)

\section{Developing organisational competence in project management}

The concept of organisational competence in project management integrates a lot of factors that should be considered while developing an organisation. First, project management activities should be aligned to the overall vision, mission and strategy of the organisation. If projects are important for the success of the organisation, their role should be mentioned in the vision, mission and strategy. Based on this, a clear strategy for the management of the projects should be derived, showing the aim of the organisation's management in this area. Consequently, project management should be linked to the strategy of the organisation, e.g. using a Balanced Scorecard for linking corporate goals with portfolio and project goals. Decisions for project selection and resource allocation could be based on such a linkage. An important side effect of this is better involvement of the top management in project-related activities.

In regard to the structural aspects, the results of an assessment could be used to derive development activities for the project management processes, methods and tools as well as the organisational structure. An important factor is the alignment of the project management processes to all internal and external processes. This alignment could be defined for special project types and categories or could be tailored by the project managers for each individual case. Synchronisation of processes is essential but not sufficient. To reach efficiency, an aligned organisational structure with distinct roles and responsibilities should be defined and empowered. Nowadays, a Project Management Office (PMO) is often used for aligning projects with related line functions as well as the project management with strategic management functions. Finally, the corporate culture should be adjusted to project-related work. A project-friendly culture (Rietiker 2009: 123) helps to achieve the intended results and to prevent conflicts.

Moreover, the availability of tangible and intangible assets should be considered while developing the organisational competence in project management. For example, sufficient financial means are needed to realise projects, investments and development activities. Tools are very important to support project management. Thus, tools (e.g. software, templates) for information exchange, documentation, communication, 
coordination and collaboration in project management should be deployed. However, intangible assets like know-how, intellectual property rights or patents are also needed to successfully complete projects.

All in all, the development of organisational competence in project management is a complex activity, covering all the above-mentioned issues. Improving only one of them is not sufficient; all of them need to be considerably developed in order to improve organisational competence as a whole. Top management could start such a program topdown. A disadvantage of this approach is that a top manager does not necessarily have enough information about the situation and the actions needed. An alternative approach could, therefore, be to encourage employees to initiate the improvements by, for example, implementing feedback mechanisms, lessons learned procedures and mutually beneficial exchange of experiences. Top management should provide strategic guidance and room to manoeuvre rather than practise micromanagement.

\section{Conclusion and outlook}

Projects are becoming more and more important for organisations in the private, public and not-for-profit sectors. Project management is faces a lot of challenges today because complex projects need to be delivered with limited resources, tight deadlines and at top quality. Some organisations perform the majority of their activities in the form of projects and therefore need a different approach to project management.

The concept of organisational competence in project management offers a new perspective for organisations to cope with a challenging environment. Organisational competence is more than the collective competence of its individuals. It is also an organisation's capability of achieving its targets by smartly combining, applying, managing and developing the available individual, strategic, structural and cultural competences as well as its assets. Hence top managers play a decisive role. They must care for a fit between the environmental conditions, the strategic orientation of the organisation and the availability of sufficient competences and assets. Top managers could enable the organisation by nurturing and maintaining a maximum of selforganisation and allowing co-evolutionary exploration and exploitation.

Assessments are used to analyse the actual status of project management and to derive necessary actions for the development of organisational competences in project management. It is not sufficient to consider only the processes applied in project management but it is necessary to analyse all the necessary factors for organisational competence. Modern assessment models take these factors into consideration better, and thereby allow organisations to develop in a sustainable manner.

In future, there is a need for more research on the constituents of the organisational competences as well as potential co-evolutionary development patterns, critical path dependencies and ways of letting the self-organisation allow for a co-evolutionary exploration and exploitation. 


\section{Reference}

Bea, F.X., Scheurer, S. \& Hesselmann, S. 2012, Projektmanagement, 2. Auflage, UVK/Lucius, Konstanz \& München.

Becker, L. 2010, Von Darwin lernen - Das PMO aus evolutorischer Perspektive in Sandrino-Arndt, B., R.L. Thomas, R.L. \& Becker, L. (eds), Handbuch Project Management Office, Symposion, Düsseldorf, 55-82.

Foss, N.J. 1996, Introduction, in Foss, N.J. \& Knudsen, C. (eds), The Emerging Competence Perspective, Routledge, New York, 13-37.

Helfat, C.E. \& Peteraf, M.A. 2003, The dynamic resource-based view: capability lifecycles, Strategic Management Journal, vol. 24, 997-1010.

IPMA 2006, IPMA Competence Baseline for Project Management, IPMA, Nijkerk.

Knudsen, C. 1996, The competence perspective - a historical view, in Foss, N.J. \& Knudsen, C. (eds), The Emerging Competence Perspective, Routledge, New York, 13-37.

Kerzner, H. 2005, Using the Project Management Maturity Model, 2nd ed., John Wiley \& Sons, Hoboken.

Maslow, A.H. 1943, A theory of human motivation, Psychological Review, vol. 50, no. 4, 370-396.

PMI 2002, Project Manager Competency Framework (PMCF), 2nd ed., PMI, Newton Square.

PMI 2008, Organizational Project Management Maturity Model (OPM3) - Knowledge Foundation, 2nd ed., PMI, Newton Square.

Prahalad, C.K. \& Hamel, G. 1990, The core competence of the corporation, Harvard Business Review, May/June 1990, 79-91.

Oxford Dictionary 2012, Online, Available: http://oxforddictionaries.com/definition/competence?q=competence (Accessed 31 April 2012).

Rietiker, S. 2006, Der neunte Schlüssel — Vom Projektmanagement zum projektbewussten Management, Haupt, Bern.

Rietiker, S. et al. 2011, Organisationale Kompetenz - eine neue Perspective für die Projektarbeit, R. Wagner (ed.), GPM Deutsche Gesellschaft für Projektmanagement, Nürnberg, 13-25.

Taatila, V. 2004, The Concept of Organisational Competence - A Foundational Analysis, University of Jyväskylä, Jyväskylä.

Teece, D.J., Pisano, G. \& Shuen, A. 1997, Dynamic capabilities and strategic management, Strategic Management Journal, vol. 18, 509-533.

Volberda, H.W. \& Lewin, A.Y. 2003, Co-evolutionary dynamics within and between firms: from evolution to co-Evolution, Journal of Management Studies, vol. 40, 2111-2136.

Wagner, R. 2010, Assessments im PM - Die Reifeprüfung für projektorientierte Organisationen, projektMANAGEMENT aktuell, 2/2010, 24-30.

\section{About the author:}

Reinhard Wagner studied electrical engineering and business administration in Germany and the United States. He first gained management experience as an officer in the German army. For more than 15 years he held executive positions in engineering with a focus on the automotive industry. He later became a consultant, trainer and coach in project and process management, sales and organisational and human resources development. He is a part-time lecturer in project management and systems engineering in the Technology Management Master's Program of the University of Augsburg. He has more than 50 relevant publications in project management. He has been involved in the development of the project management discipline by doing research and professional work for the GPM board. He leads the automotive project management and new perspectives for project work sections for developing the new DIN 69901 project management standard. He is also involved in the development of the ISO 21500 Guide for Project Management. He is a member of the editorial board of PM up to date and represents the GPM at regional, national and international forums and congresses.

Email: r.wagner@gpm-ipma.de 